\title{
Delivery and late preterm birth
}

\author{
Antonio Lanzone*, Sergio Ferrazzani, Angela Botta \\ From XX National Congress of the Italian Society of Neonatology \\ Rome, Italy. 9-11 October 2014
}

Delivery of infants who are physiologically mature and capable of successful transition to the extrauterine environment is an important priority for obstetric practitioners. During the past 15 years in the United States the percentage of infants born before 40 weeks' gestation has dramatically increased and the percentage of infants born after 40 weeks' gestation has decreased. In this shift several factors have been implicated: increased medical surveillance and interventions, increased multifetal pregnancies, maternal obesity (risk for preeclampsia, diabetes and other complications), maternal autonomy, route and timing of delivery.

Birth before fetal maturity contributes to short-term and long-term morbidity and mortality in late preterm $\left(34^{+0}\right.$ to $36^{+6}$ weeks' gestation). Age stratified cohort studies confirms that adverse neonatal outcome decrease with increasing gestational age independent of delivery mode.

Because of the known morbidity and mortality associated with late preterm birth, iatrogenic delivery in this period has become a major concern. Preterm birth has been characterized as either "spontaneous" or "indicated." For the most part, spontaneous late preterm births are difficult to avoid, whereas the term "indicated" implies that the delivery was necessary for maternal or fetal benefit. Gyamfi-Bannerman and colleagues found that $56.7 \%$ of late preterm non spontaneous deliveries were non-evidence based, concluding that more data were needed to justify many indications. A recent workshop by the Society for Maternal-Fetal Medicine developed consensus recommendations regarding the gestational age for delivery. These recommendations and those of the American College of Obstetricians and Gynecologists (ACOG) are based on the balance between maternal and newborn risks of early delivery with the risk of further continuation of pregnancy.

To decrease the mortality and morbidity associated with late preterm births, prevention is one of the key

\footnotetext{
Istituto di Clinica Ostetrica e Ginecologica, Università Cattolica del S. Cuore.,
} Rome, Italy and take full advantage of:

- Convenient online submission

- Thorough peer review

- No space constraints or color figure charges

- Immediate publication on acceptance

- Inclusion in PubMed, CAS, Scopus and Google Scholar

- Research which is freely available for redistribution Submit your manuscript at
www.biomedcentral.com/submit C BioMed Central 